\title{
A Vision for a new electronic journal based on a long tradition
}

\author{
STEFAN EMEIS $^{1, *}$ and VOLKER WULFMEYER ${ }^{2}$ \\ ${ }^{1}$ Institute of Meteorology and Climate Research, Karlsruhe Institute of Technology, Campus Alpin, \\ Garmisch-Partenkirchen, Germany \\ ${ }^{2}$ Institute of Meteorology and Physics, University of Hohenheim, Stuttgart, Germany
}

Presently, Meteorologische Zeitschrift is facing several new challenges. In recent years, the ways of scientific publishing have changed dramatically. Printed journals paid by subscribers, which served as the only means of rapid scientific exchange and discussion for more than two hundred years, are losing their unique role. For about a decade, new publication formats have been emerging from web-based technologies. These are freely available and are paid for either by the authors or by institutions with a vital interest in scientific communication. Printed copies are produced for a few central-reference libraries only.

Meteorologische Zeitschrift with its nearly 150 years of tradition in publishing peer reviewed scientific papers has responded to this development by introducing an online submission and review system as early as 2007. January 2012 marked another milestone, as Meteorologische Zeitschrift began offering Open Access papers as a standard publication model. It is true that now authors always have to pay page charges for their publications. But these charges were lowered considerably (now $€ 108.40$ instead of $€ 179$ per page previously) which now include all-colour graphics and images. No extra colour charges any longer!

This attractive publication model of Meteorologische Zeitschrift allows papers to represent complex data in a contemporary way; it is fully competitive to comparable scholarly journals available on the internet. Open access papers have considerably increased visibility in the scientific community which will help our authors to improve their publication and citation ratings. Last but not least, the page charges ensure that the high level of quality in our journal can be maintained. Furthermore, accepted articles and special issues are published without any delay and no extra costs using a Fast Track option ahead of the distribution of printed copies.

Impact factors of Meteorologische Zeitschrift have been rising constantly, reaching 1.875 (five-year impact factor) in 2011. Further increases of these bibliometric parameters are expected as Met.Z. transits to a full Open Access journal. We hope this will attract even more high-quality manuscripts on current topics of meteorological research.

On February 1, 2013 a change in editorship of Meteorologische Zeitschrift became effective with Stefan Emeis succeeding Volker Wulfmeyer, who successfully guided this journal since 2007. Volker Wulfmeyer worked with outstanding commitment for this journal. During his term, the internet-based online submission and review system became operational. It enables authors, reviewers and editors to track submissions to Meteorologische Zeitschrift within seconds from all over the world. Volker Wulfmeyer convinced all stakeholders in this journal that a rapid conversion to Open Access publishing is necessary. And the change towards this publication type is nearly complete, indeed. We thank Volker Wulfmeyer for the great effort he devoted to Meteorologische Zeitschrift.

The new editor-in-chief and his co-editors intend to complete the transition towards a full electronic journal, but the roots of Meteorologische Zeitschrift with its long tradition since 1866 will remain discernible. One element in this long-standing tradition will be the continuation of the "Classic Paper" series in Meteorologische Zeitschrift. This series will make available seminal papers from the first century of Meteorologische Zeitschrift to a modern global readership. The papers are translated into English and their re-publication is accompanied by a commentary putting them into a modern perspective.

\footnotetext{
${ }^{*}$ Corresponding author: Stefan Emeis, Institut für Meteorologie und Klimaforschung, Atmosphärische Umweltforschung (IMK-IFU), Karlsruher Institut für Technologie (KIT), Garmisch-Partenkirchen, e-mail: stefan.emeis@kit.edu
} 
The electronic submission system of the journal will be updated continuously and will serve as a means to further accelerate the publication process of this journal. Together with these updates we will continue to work further on speeding up publication without compromising the quality of the peer review process. With these changes and efforts Meteorologische Zeitschrift is expected to be a reliable and timely publication service for all readers and authors interested in meteorology in the next years and decades - in a tradition which is now nearly 150 years old.

Stefan Emeis and Volker Wulfmeyer

The Publishers of Meteorologische Zeitschrift, Borntraeger Science Publishers, Stuttgart, Germany wish to thank Volker Wulfmeyer for his outstanding support, engagement and leadership as Editor in Chief of MetZet since 2007.

We are confident that Stefan Emeis will continue developing Meteorologische Zeitschrift with the same verve and competence as Volker Wulfmeyer did for many years; we would like to thank him for assuming the Chief Editorship of MetZet. The Publishers encourage chief editors, editors, reviewers and authors to actively support MetZet on its way to increasing visibility and well established scientific journal.

Andreas Nägele Borntraeger Science Publishers, Stuttgart, Germany 